\title{
Two-Step Vapor Deposition of Self-Catalyzed Large-Size Pbl2 Nanobelts for High-Performance Photodetectors
}

DOI:

10.1039/C8TC01180J

Document Version

Accepted author manuscript

Link to publication record in Manchester Research Explorer

\section{Citation for published version (APA):}

Han, M., Sun, J., Bian, L., Wang, Z., Zhang, L., Yin, Y., Gao, Z., Li, F., Qian Xin, He, L., Han, N., Song, A., \& Yang, Z-X. (2018). Two-Step Vapor Deposition of Self-Catalyzed Large-Size Pbl2 Nanobelts for High-Performance Photodetectors. Journal of Materials Chemistry C, 6, 5746-5753. https://doi.org/10.1039/C8TC01180J

\section{Published in:}

Journal of Materials Chemistry C

\section{Citing this paper}

Please note that where the full-text provided on Manchester Research Explorer is the Author Accepted Manuscript or Proof version this may differ from the final Published version. If citing, it is advised that you check and use the publisher's definitive version.

\section{General rights}

Copyright and moral rights for the publications made accessible in the Research Explorer are retained by the authors and/or other copyright owners and it is a condition of accessing publications that users recognise and abide by the legal requirements associated with these rights.

\section{Takedown policy}

If you believe that this document breaches copyright please refer to the University of Manchester's Takedown Procedures [http://man.ac.uk/04Y6Bo] or contact uml.scholarlycommunications@manchester.ac.uk providing relevant details, so we can investigate your claim.

\section{OPEN ACCESS}




\section{Journal Name}

\section{ARTICLE}

\section{Two-Step Vapor Deposition of Self-Catalyzed Large-Size $\mathrm{Pbl}_{2}$ Nanobelts for High-Performance Photodetectors}

Received 00th January 20xx Accepted 00th January 20xx

DOI: $10.1039 / x 0 x x 00000 x$

www.rsc.org/

\author{
Mingming Han, $\ddagger^{\mathrm{a}}$ Jiamin Sun, $\mp^{\mathrm{ab}}$ Luozhen Bian, $\ddagger^{\mathrm{ab}}$ Zhou Wang, ${ }^{\mathrm{c}}$ Lei Zhang, ${ }^{\mathrm{d}}$ Yanxue Yin, ${ }^{\mathrm{a}}$ Zhaofeng \\ Gao, ${ }^{a}$ Fulin Li, ${ }^{a}$ Qian Xin, ${ }^{a}$ Longbin He, ${ }^{d}$ Ning Han, ${ }^{* c}$ Aimin Song ${ }^{\mathrm{a}}$ and Zai-xing Yang*ab
}

\section{Introduction}

In the past decade, layer-structured materials with in-plane covalent bonding and weak interlayer interactions (van der Waals) have attracted extensive research attentions, owing to the possibility of thinning down to atomically thick twodimensional (2D) materials. ${ }^{1-13}$ As a typical layered perovskite derivative, lead iodide $\left(\mathrm{Pbl}_{2}\right)$ has attracted extensive research attention in solar cells, photodetectors and other optoelectronic devices, ${ }^{14-26}$ due to its direct bandgap of 2.28-2.5 $\mathrm{eV}$ and tunable optoelectronic properties. ${ }^{16,19-27}$ Layered $\mathrm{Pbl}_{2}$ material is composed of covalently bonded $\mathrm{I}-\mathrm{Pb}-\mathrm{I}$ repeating units stacked along the c-axis by van der Waals interlayer interaction. ${ }^{28}, 29 \mathrm{Up}$ to now, low dimensional $\mathrm{Pbl}_{2}$ nanostructures of nanosheets, 19-22, 24, 26 nanowires ${ }^{19}, 23,27$ and atomically thin monolayers 22 have been prepared by a simple synthesis method of vapor deposition. In the reported vapor deposition of $\mathrm{Pbl}_{2}$ nanostructures, one-dimensional (1D)

\footnotetext{
a. Center of Nanoelectronics and School of Microelectronics, Shandong University, Jinan 250100, P. R. China. E-mail: zaixyang@sdu.edu.cn

b. Shenzhen Research Institute of Shandong University, Shandong University, Shenzhen 518057, P. R. China

State Key Laboratory of Multiphase Complex Systems, Institute of Process Engineering, Chinese Academy of Sciences, Beijing 100190, P. R. China. E-mail: nhan@ipe.ac.cn

d. SEU-FEI Nano-Pico Center, Key Lab of MEMS of Ministry of Education, Collaborative Innovation Center for Micro/Nano Fabrication, Device and System, Southeast University, Nanjing 210096, P. R. China

$¥$ These authors contributed equally to this work.

† Electronic Supplementary Information (ESI) available. See DOI: 10.1039/x0xx00 $000 x$
}

nanowires followed a chemical vapor deposition (CVD) process, ${ }^{19}, 23,27$ otherwise, two-dimensional (2D) nanosheets followed a physical vapor deposition (PVD) process. ${ }^{19,} 21,22,26$ For example, Meyers et al. reported recently the self-catalyzed vapor-liquid-solid (VLS) growth of $\mathrm{Pbl}_{2}$ nanowires in a CVD growth procedure. ${ }^{23}$ On the other hand, highly uniform 2D Pbl 2 nanosheets have been prepared by Wang et al. via a space confined PVD process. ${ }^{26}$ Furthermore, Lan et al. pointed out that the surface roughness of the growth substrates played a critical role on the nucleation of $\mathrm{Pbl}_{2}$ microplanes in a PVD growth of $2 \mathrm{D} \mathrm{Pbl}$ nanosheets. ${ }^{21}$ However, for photodetector application, 1D nanowires have a relatively smaller absorption area leading to low current density and 2D nanosheets with a finite size necessitate complicated device metallization such as Au nanowire mask method. ${ }^{19,} 22$ Therefore, it is highly desirable to synthesize large-size 2D materials for easily fabricated photodetectors.

Combining the geometry of 1D nanowires with 2D nanosheets, quasi $1 \mathrm{D}$ nanostructure of $2 \mathrm{D}$ nanobelt is considered as a promising candidate for achieving high performance and easily fabricated optoelectronic devices. Up to now, most of the works are concentrated on the $2 \mathrm{D}$ morphologies with grain size on the order of tens of micrometers, $19,22,24,26$ there are limited reports focusing on the large-scale synthesis of $2 \mathrm{D} \mathrm{Pbl} 2$ nanobelts with size up to hundreds of micrometers in a CVD process. With a size up to hundreds of micrometers, it will become easy to handle the authentic optoelectronic applications of 2D nanomaterials. In this work, large-scale $\mathrm{Pbl}_{2}$ nanobelts with length up to hundreds of micrometers $(>100 \mu \mathrm{m})$ have been prepared successfully on amorphous $\mathrm{SiO}_{2} / \mathrm{Si}$ substrates via a 
two-step thermal evaporation process. Firstly, the hexagonal layered $\mathrm{Pbl}_{2}$ nanosheets are formed on the growth substrate when the source material of $\mathrm{Pbl}_{2}$ is at a low thermal temperature, following a PVD growth process. With the increase of the heating temperature, $\mathrm{Pbl}_{2}$ nanobelts grow from the as-grown $\mathrm{Pbl}_{2}$ nanosheet seed layer by a self-catalyzed CVD process. The mass of the source material, growth temperature and growth time are found to be the essential issues on the controllable growth of large-size and high-density $\mathrm{Pbl}_{2}$ nanobelts. Without adopting any sophisticated device fabrication process, the as-prepared lager-size $\mathrm{Pbl}_{2}$ nanobelts can be configured into the simple photoconductors by shadow mask, exhibiting impressive photosensing properties with a small dark current of $4 \mathrm{pA}$, an impressive ON/OFF current ratio of $10^{3} \sim 10^{4}$, and a good responsivity of $13 \mathrm{~mA} \mathrm{~W}^{-1}$ at a wavelength of $445 \mathrm{~nm}$, an excellent stability and an efficient time response (i.e., rise and decay time constants of 425 and 41 $\mathrm{ms}$, respectively). All these results confirm evidently the technological potency of these large-size and highly crystalline 2D $\mathrm{Pbl}_{2}$ nanobelts for easily-fabricated high-performance photodetectors.

\section{Experimental}

\section{$\mathrm{Pbl}_{2}$ nanobelts synthesis}

Large-size $\mathrm{Pbl}_{2}$ nanobelts studied here were synthesized by employing a solid-source CVD method in a horizontal tube furnace, similar to the reported literatures. ${ }^{19,}$ 21-23, 26, 27, 30-32 In brief, the solid source of $\mathrm{Pbl}_{2}$ powder (99.99\% purity) was located in the upstream and the growth substrate of $\mathrm{SiO}_{2} / \mathrm{Si}$ was located in the downstream of a two-zone tube furnace with a distance of $5.5 \mathrm{~cm}$. Argon (99.999\% purity) was used as the carrier gas to transport the thermally vaporized material to the downstream. Prior to heating, the quartz tube was purged with 50 standard cubic centimeter ( $\mathrm{sccm}$ ) Ar for $0.5 \mathrm{~h}$. During growth, the source material of $\mathrm{Pbl}_{2}$ was heated to $550{ }^{\circ} \mathrm{C}$ in $30 \mathrm{~min}(\sim 18$ ${ }^{\circ} \mathrm{C} \mathrm{min}^{-1}$ ) and was kept at this temperature for $20 \mathrm{~min}$. As shown in the temperature distribution of downstream zone (Fig. S1, ESI. $\dagger)$, the growth temperature of the large-size $\mathrm{Pbl}_{2}$ nanobelts is deduced as $\sim 364^{\circ} \mathrm{C}$. After growth, heating of $\mathrm{Pbl}_{2}$ was stopped and cooled to room temperature naturally in the Ar flow. Eventually, a layer of orange yellow product could be collected on the substrate.

\section{Materials characterization}

Surface morphologies of the as-grown large-size $\mathrm{Pbl}_{2}$ nanobelts were examined using a scanning electron microscope (SEM, Nova NanoSEM 450, FEl Company) and a transmission electron microscope (TEM, FEI TECNAI 20). The thickness of the asprepared large-size $\mathrm{Pbl}_{2}$ nanobelts were measured by atmoic force microscope (AFM, CSPM5500, Being Nano-Instruments). The crystal structure and crystallinity of the products were verified by X-ray diffraction (XRD, D8 Advance, Bruker) and selected area electron diffraction (SAED) attached to TEM. Elemental identifications were performed using an energy dispersive $x$-ray spectroscopy (EDS) detector attached to SEM to measure the chemical composition of the obtained nanobelts.
For the TEM studies, the nanobelts were scratched onto the copper grid for the corresponding characterization. Raman and Photoluminescence (PL) spectra followed PL and Raman mappings were measured by a Raman spectrometer (inVia Reflex, Renishaw) with $532 \mathrm{~nm}$ laser and $325 \mathrm{~nm}$ laser, respectively. Corresponding absorption spectrum was measured using UV-vis spectrometer (TU-1901, Beijing Puxitongyong Company), which was converted to absorbance spectra $(\alpha=-B \ln (r)$, where $B$ is a film thickness related coefficient).

Nanobelts devices fabrication and photo-electrical property measurements

For the device fabrication, the nanobelts were firstly transferred onto the degenerately doped p-type Si substrates with a $300 \mathrm{~nm}$ thick thermally grown gate oxide layer by using a physical dry transfer technique. Stainless steel grid was next used as the shadow mask and attached onto the substrate. Ti $(5 \mathrm{~nm})$ and $\mathrm{Au}$ $(200 \mathrm{~nm})$ thin films were deposited via electron beam evaporation as the electrical contact electrode. The electrical performance of the fabricated device was then characterized with a standard Lakeshore electrical probe station and a Keithley 4200 semiconductor analyzer. Laser diodes with wavelength of $375,445,532,630$ and $730 \mathrm{~nm}$ were used as light source for the photodetector measurement, while the power of the incident irradiation was tuned and measured using a power meter from 15 to $150 \mathrm{~mW} \mathrm{~cm}^{-2}$.

\section{Result and discussions}

SEM together with EDS technology are adopted here to characterize the morphology and composition of the asprepared lager-size $\mathrm{Pbl}_{2}$ nanobelts. With an optimal growth condition of $0.015 \mathrm{~g} \mathrm{Pbl}_{2}$ powder as source material, lager-size $\mathrm{Pbl}_{2}$ nanobelts with high density have been prepared successfully on amorphous substrate at $550{ }^{\circ} \mathrm{C}$ for $20 \mathrm{~min}$ in a $50 \mathrm{sccm}$ Ar atmosphere. As shown in Fig. 1a, the as-grown sample shows a morphology of nanobelt with a smooth surface and a length of $>100 \mu \mathrm{m}$. At the same time, the composition of this large-size nanobelt is detected by EDS, showing the nanobelt body consists of $\mathrm{Pb}$ and I elements in the atomic ratio of 1:2. As shown in Fig. S2, ESI. $\dagger$, the thickness of the asprepared large-size $\mathrm{Pbl}_{2}$ nanobelts is measured as $287 \pm 94 \mathrm{~nm}$ by AFM. Furthermore, the smooth surface of the as-prepared $\mathrm{Pbl}_{2}$ nanobelts is also verified by TEM in Fig. 1b. SAED pattern in the inset displays the characteristic hexagonal symmetry of diffraction spots with the zone axis of [0001], suggesting that the nanobelts are grown in the $\langle 01 \overline{1} 0\rangle$ direction with an excellent crystallinity. Based on the XRD pattern of Fig. 1c, the as-prepared $\mathrm{Pbl}_{2}$ nanobelts is the hexagonal $\mathrm{Pbl}_{2}$ structure (JCPDS: 07-0235) without any other impurity phases, indicating the nanobelts being pure $\mathrm{Pbl}_{2}$ crystals. ${ }^{16,}{ }^{21}$ This is in line with the SAED result. It is worth pointing out that nanospheres are found at the tip of the as-prepared nanobelts (Fig. 1d), indicating the as-prepared nanobelts follow a VLS growth mechanism. ${ }^{33,} 34$ It is a common phenomenon of nanoparticles existing on the as-prepared $\mathrm{Pbl}_{2}$ nanobelts, as shown in Fig. S3, 


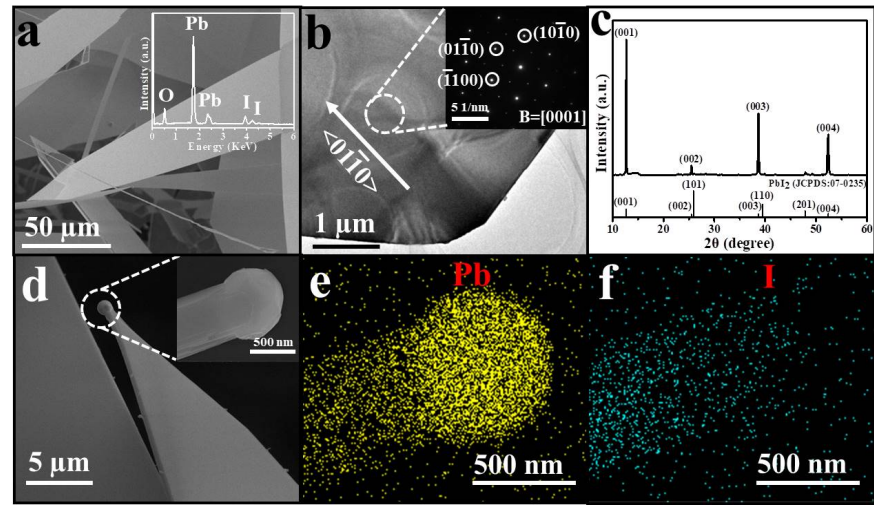

Fig.1 Morphology, microstructure and composition characterization of the asprepared large-size $\mathrm{Pbl}_{2}$ nanobelts. (a) SEM image of as-prepared $\mathrm{Pbl}_{2}$ nanobelts, inset is the corresponding EDS spectrum; (b) TEM image of the as-prepared $\mathrm{PbI}_{2}$ nanobelts, inset is the corresponding SAED image; (c) XRD pattern of the asprepared $\mathrm{Pbl}_{2}$ nanobelts; (d) SEM of the tip section of $\mathrm{Pbl}_{2}$ nanobelts, inset is the high-resolution SEM image; (e, $\mathrm{f}$ ) EDS mapping images of $\mathrm{Pb}$ and $\mathrm{I}$ of $\mathrm{Pbl}_{2}$ nanobelts in Figure $d$ inset.

ESI. $\dagger$. The sizes of the observed nanoparticles are $200-1200 \mathrm{~nm}$. The detailed growth mechanism of this kind of large-size $\mathrm{Pbl}_{2}$ nanobelts will be discussed later. As presented in Fig. 1e \& $f$, the EDS elemental mapping of the same nanobelts (inset of Fig. 1d) illustrates the homogeneous distribution of $\mathrm{Pb}$ and $\mathrm{I}$ atoms along the nanobelts body. In the meanwhile, it is found that the tip mainly contains $\mathrm{Pb}$ atom, whereas the I content drops drastically once passing the tip/nanobelt interface, as shown in Fig. S4, ESI.†. In short, all these demonstrate the well-controlled surface morphology, crystallinity and stoichiometry of $\mathrm{Pbl}_{2}$ nanobelts achieved with a simple vapor deposition growth technique.

For guiding the controllable growth of large-size 2D nanomaterials, the growth mechanism of the as-prepared $\mathrm{Pbl}_{2}$ nanobelts is studied in detailed by issues of the mass of source material, growth temperature, and growth time. As shown in SEM images of Fig. 2, one can see that the mass of $\mathrm{Pbl}_{2}$ plays an important effect on the as-prepared $\mathrm{Pbl}_{2}$ morphology. With a low content of $0.005 \mathrm{~g} \mathrm{Pbl}_{2}$ powder, only nanosheets are found on the substrate. When the mass of $\mathrm{Pbl}_{2}$ powder reaches 0.01 $\mathrm{g}$, large-size $\mathrm{Pbl}_{2}$ nanobelts with low density can be observed, possibly caused by the inadequate $\mathrm{Pbl}_{2}$ or $\mathrm{Pb} / \mathrm{I}$ vapor during the nanobelt growth process. Afterwards, as the mass of $\mathrm{Pbl}_{2}$ powder exceeds the optimal content of $0.015 \mathrm{~g}$, there are small nanosheets grow on the surface of the large-size $\mathrm{Pbl}_{2}$ nanobelts, as marked by red circles in Fig. 2c\&d. In a word, as $\mathrm{Pbl}_{2}$ has a relatively low melting point of $406{ }^{\circ} \mathrm{C}, 35$ it evaporates easily to form the vapor phase precursors. Therefore, too little source such as $0.005 \mathrm{~g}$ would be all evaporated to form the nanosheets, leading to no successive nanobelt growth. While higher source mass would provide not only the precusors for nanosheet but also the nanobelt growth. On the other hand, the effect of growth temperature on the controllable growth of $\mathrm{Pbl}_{2}$ nanobelts is also studied and the corresponding morphology can be found in Fig. S5, ESI. $\dagger$. Namely, at a low growth temperature of $490^{\circ} \mathrm{C}$, nanosheets dominated the morphology of the as-grown sample. With the increase of growth

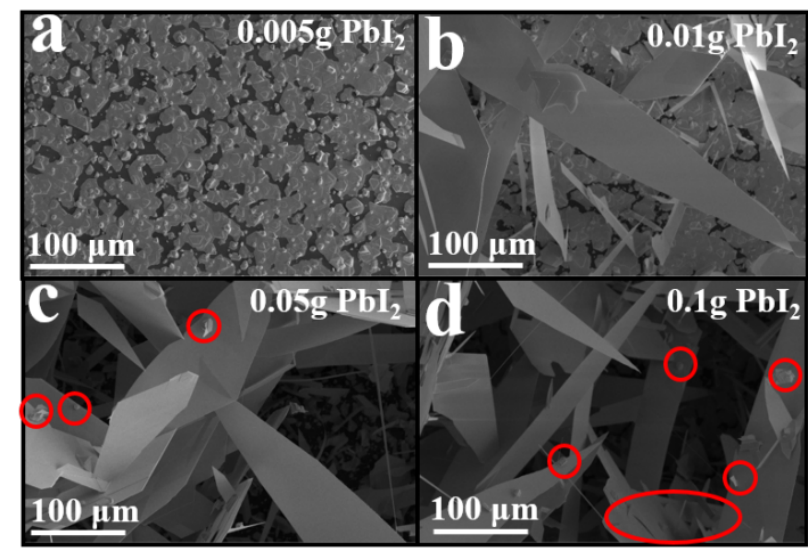

Fig.2 Effect of source material mass on the nanobelts growth. (a, b, c, d) SEM images of the as-prepared $\mathrm{Pbl}_{2}$ samples grown with different source material masses of $0.005,0.01,0.05$ and $0.1 \mathrm{~g}$.

temperature, the amount of nanobelts increases. However, the width of these as-grown nanobelts is narrow, possibly caused by the inactive $\mathrm{Pbl}_{2}$ or $\mathrm{Pb} / \mathrm{I}$ vapor. In the end, the growth time is also found to be a significant element on the controllable growth of large-size $\mathrm{Pbl}_{2}$ nanobelts, as shown in Fig. 3 . With a growth time of $1 \mathrm{~min}$, nanosheets together with very short nanobelts are observed on the substrate. When the growth time prolongs to $5 \mathrm{~min}$, large-size $\mathrm{Pbl}_{2}$ nanobelts with very low density are prepared. Importantly, with a high-resolution SEM images, one can see that the nanobelts are grown from the nanosheets randomly. That is, some nanobelts are parallel to the nanosheets and the others are tilted to the nanosheets. The tilt angle can be estimated from XRD pattern in Fig. 1c, where the dominant peaks are related to c-plane of $\mathrm{Pbl}_{2}$ while only a weak peak attributed to (201). Therefore, it is plausible that most nanobelts tilt at an angle of $\sim 75^{\circ}$ which is the one between (201) and (001) planes. It is worth pointing out that the success control growth of the large-size $\mathrm{Pbl}_{2}$ nanobelts is benefited from the slow heating rate (reach $550{ }^{\circ} \mathrm{C}$ in $30 \mathrm{~min}$ ) of the source material. With a rapid heating rate of the source material (reach $550{ }^{\circ} \mathrm{C}$ in $7 \mathrm{~min}$ ), there are only nanoparticles on the substrate (shown in Fig. S6, ESI. $\dagger$ ). Anyway, this phenomenon of nanostructures growing from its seed layer is usually found in the growth process of other kinds of nanomaterials. ${ }^{36-39}$ In a word, by adopting an optimal growth condition of $0.015 \mathrm{~g} \mathrm{Pbl}_{2}$ powder evaporated at $550^{\circ} \mathrm{C}$ for $20 \mathrm{~min}$, high-quality and largesize $\mathrm{PbI}_{2}$ nanobelts with a high density can be prepared on the amorphous $\mathrm{SiO}_{2} / \mathrm{Si}$ substrate.

Based on the above discussion, a possible growth mechanism can be proposed here, as shown in Fig. 3e-h. With a slow heating rate of source material, the growth of large-size $\mathrm{Pbl}_{2}$ nanobelts can be divided into two stages. At the first stage, $\mathrm{Pbl}_{2}$ nanosheets grow on the smooth substrate by a PVD process, as reported elsewhere. ${ }^{19}, 21,22,26$ Namely, at a low growth temperature, the new coming $\mathrm{Pbl}_{2}$ species would get adsorbed on the $\mathrm{Pbl}_{2}$ nuclei as well as on the substrate surface and then be migrated to the growth sites. Similar to the other types of layered materials, the growth sites of layered $\mathrm{Pbl}_{2}$ nanosheets are always located at the edges as illustrated in Fig. 3e. As a 


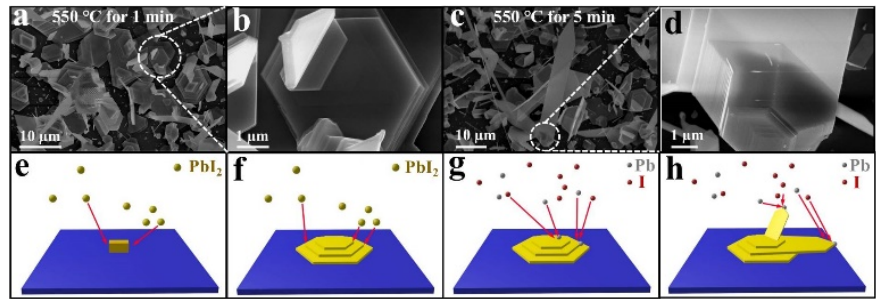

Fig.3 Possible growth mechanism of the as-prepared large-size $\mathrm{Pbl}_{2}$ nanobelts. (a, b) SEM images of $\mathrm{Pbl}_{2}$ sample grew at $550{ }^{\circ} \mathrm{C}$ for $1 \mathrm{~min}$; (c, d) SEM images of $\mathrm{Pbl}_{2}$ sample grew at $550{ }^{\circ} \mathrm{C}$ for $5 \mathrm{~min} ;(\mathrm{e}, \mathrm{f}, \mathrm{g}, \mathrm{h})$ Schematic illustration of the possible growth process of the as-prepared large-size $\mathrm{Pbl}_{2}$ nanobelts.

result, $\mathrm{Pbl}_{2}$ nuclei would then be expanded in the in-plane direction and grown into a large sheet-like structure, as shown in Fig. 3f. With the increase of growth temperature, the evaporated $\mathrm{Pbl}_{2}$ would mostly be decomposed into elemental or molecular $\mathrm{Pb}$ and I species. $\mathrm{Pb}$ has a higher boiling point of $1749{ }^{\circ} \mathrm{C},{ }^{40}$ but a low melting point of $327.4{ }^{\circ} \mathrm{C} ;{ }^{40}$ therefore, it is possible for $\mathrm{Pb}$ species to aggregate into $\mathrm{Pb}$ liquid droplets during the growth. This result has been verified by the EDS mapping of the as-prepared $\mathrm{Pbl}_{2}$ nanobelts in Fig. 1e-f. Consequently, the $\mathrm{Pbl}_{2}$ nanobelts can then be grown after the catalytic supersaturation of $\mathrm{Pbl}_{2}$ in the $\mathrm{Pb}$ liquid droplets via VLS mechanism. However, with a rapid heating rate of source material, there is not abundant time for the PVD growth of seed layer of $\mathrm{Pbl}_{2}$ nanosheets on the substrate, and thus no nanobelts can be prepared (Fig. S6, ESI. $\dagger$ ). With a low content of source material, $\mathrm{Pbl}_{2}$ powder would be evaporated off at the first stage of nanosheets growth, resulting in insufficient source vapor for the nanobelts growth. In this case, only nanosheet can be found on the substrate, as shown in Fig. 2a. With an excessive source material, the third PVD/CVD growth process of $\mathrm{Pbl}_{2}$ nanobelts started at the smooth surface of the as-grown large-size $\mathrm{Pbl}_{2}$ nanobelts. As a result, many irregular nanosheet/nanobelts are observed on the surface of the largesize nanobelts (shown in Fig. 2c\&d). In case of growth temperature, only PVD growth process occurrs at a low growth temperature, and the as-prepared sample shows nanosheets with a few of nanobelts (shown in Fig. S5a, ESI. $\dagger$ ). However, with the increase of growth temperature, the decomposition of $\mathrm{Pbl}_{2}$ occurred and the contents of $\mathrm{Pb}$ and I vapor increase simultaneously, resulting in the success growth of large-size $\mathrm{Pbl}_{2}$ nanobelts (shown in Fig. S5b-d, ESI. $\dagger$ ). In short, with a slow heating rate of source material, high-quality, high-density and large-size $\mathrm{Pbl}_{2}$ nanobelts have been prepared successfully from a seed layer of $\mathrm{Pbl}_{2}$ nanosheets by a VLS growth mechanism in a two-step thermal evaporation process.

Raman, UV-vis absorption and PL spectra are carried out to investigate the optical properties of the as-prepared large-size $\mathrm{Pbl}_{2}$ nanobelts. The Raman data of the $\mathrm{Pbl}_{2}$ nanobelts excited by a $532 \mathrm{~nm}$ wavelength laser is recorded in Fig. 4a. Three dominant Raman peaks are clearly observed at the location of $73.8,97.2$, and $112.7 \mathrm{~cm}^{-1}$, corresponding to the $E_{g}, A_{1 g}$, and $A_{2 u}$ Raman vibration modes in $2 \mathrm{H}$ polytype of $\mathrm{Pbl}_{2}$, respectively. ${ }^{20}$, 26, 41, 42 Similar with the reported $2 \mathrm{D} \mathrm{Pbl}$, nanostructures, the peak intensity of the as-prepared large-size $\mathrm{Pbl}_{2}$ nanobelts is

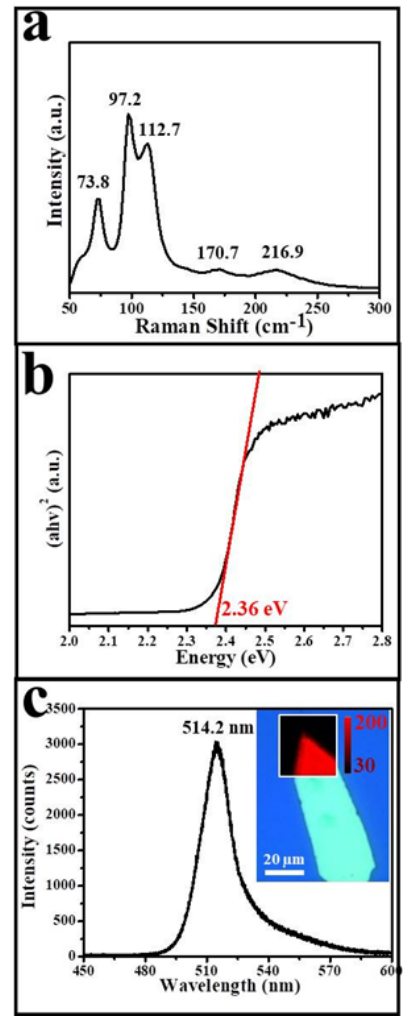

Fig.4 Optical properties of the as-prepared large-size $\mathrm{Pbl}_{2}$ nanobelts. ( $\mathrm{a}, \mathrm{b}, \mathrm{c}$ ) Raman, UV-vis absorption and PL spectra of the as-prepared $\mathrm{Pbl}_{2}$ nanobelts, respectively. Inset of Figure $\mathrm{c}$ is the $2 \mathrm{D} \mathrm{PL}$ mapping image at the tip of the asprepared nanobelt.

strong and the corresponding peak's full width at half-maximum (FWHM) is small,19-22, 24, 26 indicating a high crystal quality. UVvis absorption spectrum is employed to study the bandgap of the as-prepared large-size $\mathrm{Pbl}_{2}$ nanobelts. The experimental values of the bandgap can be obtained through a Kubelka-Munk (K-M) transformation of the UV-visible spectrum: $[F(R) h v]^{2}$, where $F(R)$ is the diffuse reflectance spectrum. ${ }^{43-45}$ As shown in Fig. $4 \mathrm{~b}$, the calculated bandgap of $\mathrm{Pbl}_{2}$ nanobelts is about 2.36 $\mathrm{eV}$, which coincides well with the previous reports. ${ }^{16,19-22,24-27}$ In addition to Raman and UV-visible spectra, room temperature $\mathrm{PL}$ spectrum of the as-prepared large-size $\mathrm{Pbl}_{2}$ nanobelts is also obtained, as shown in Fig. 4c. The sharp peak centered at 514 $\mathrm{nm}(2.41 \mathrm{eV})$ is in perfect agreement with the bandgap of 2.36 $\mathrm{eV}$ determined from the UV-visible spectrum. The strong peak intensity and the narrow FWHM of the PL peak further verify the high crystalline quality of the as-grown large-size $\mathrm{Pbl}_{2}$ nanobelts. This result also can be deduced from the $2 \mathrm{DPL}$ mapping image of the as-prepared large-size $\mathrm{Pbl}_{2}$ nanobelts. As depicted in the inset of Fig. 4c, the color contrast of PL mapping is very uniform, indicating the uniform crystallinity of the largesize $\mathrm{PbI}_{2}$ nanobelts. It is noticable to point out that there is no 2D PL mapping signal from the $\mathrm{Pb}$ nanoparticle, resulting in a black zone at the top of the as-prepared $\mathrm{Pbl}_{2}$ nanobelt, as shown in Fig. S7, ESI. $\uparrow$. This phenomenon also can be found in 2D Raman mapping at a frequency of $97.2 \mathrm{~cm}^{-1}$ ( $\mathrm{Pbl}_{2}$ domian). However, in Fig. 4c, owing to the low resolution, the black sphere zone of the $\mathrm{Pb}$ nanoparticle is so small that it cannot be 


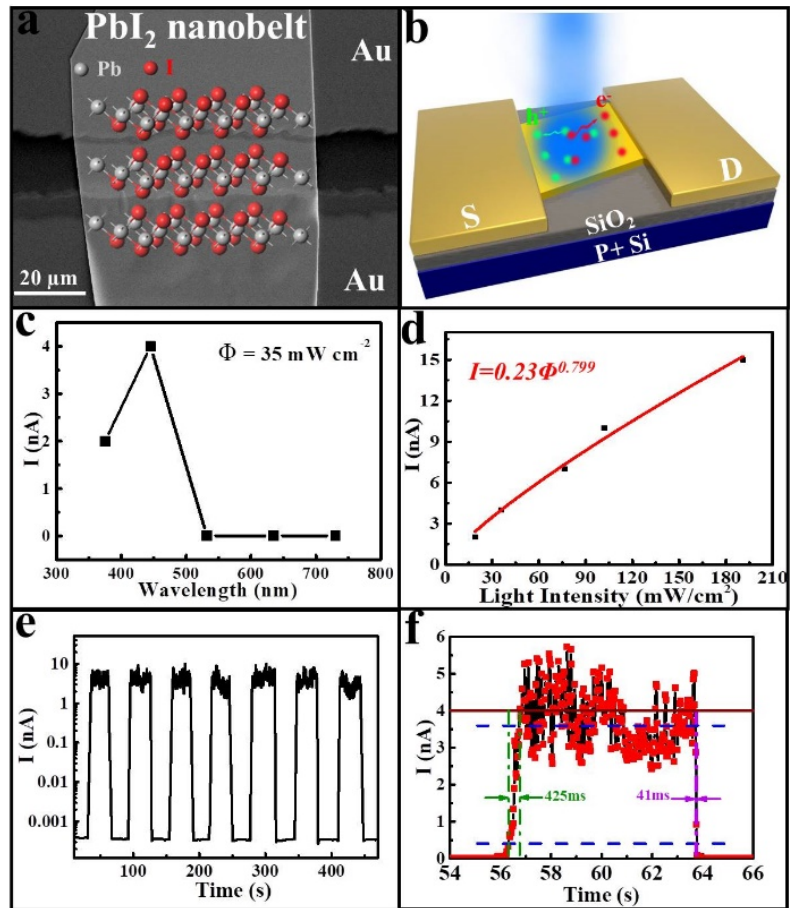

Fig. 5 Photoresponse of the as-prepared large-size $\mathrm{Pbl}_{2}$ nanobelts photodetectors. $(\mathrm{a}, \mathrm{b})$ SEM image and device schematic of the as-fabricated photodetector, inset in Figure a is the atomic model of $\mathrm{Pbl}_{2}$ crystal; (c) Photocurrent as a function of incident light wavelength with an intensity of $35 \mathrm{~mW} \mathrm{~cm}^{-2}$; (d) Photocurrent as a function of incident light intensity; (e) The device output current as a function of time under the chopped light illumination. The light intensity is $35 \mathrm{~mW} \mathrm{~cm}^{-2}$. (f) the rise time and decay time constants. The bias voltage for (c)-(f) is $5 \mathrm{~V}$.

seen clearly. In short, all these results strongly suggest the potential application of the as-prepared large-size $\mathrm{Pbl}_{2}$ nanobelts with high crystallinity for high-performance optoelectronic devices.

As a direct bandgap semiconductor, besides the understanding of growth kinetics and mechanisms, it is interesting to assess the optoelectronic properties of the as-prepared large-size $\mathrm{Pbl}_{2}$ nanobelts. In this case, photodetector is fabricated on the $\mathrm{SiO}_{2} / \mathrm{Si}$ substrate by a simple shadow mask process ( $\mathrm{Si}$ substrate with a $300 \mathrm{~nm} \mathrm{SiO}$ insulating top layer) and is electrically characterized under illumination. Fig. 5a is the SEM image of the as-fabricated photodetector with a $\mathrm{PbI}_{2}$ nanobelt area of 879.8 $\mu \mathrm{m}^{2}$. Inset is the atomic model of $\mathrm{Pbl}_{2}$ crystal, displaying $\mathrm{Pbl}_{2}$ is a layered material, which composed of covalently bonded I-PbI repeating units stacked along the $\mathrm{c}$-axis and the van der Waals interlayer interaction. Fig. $5 b$ is the device schematic of the asfabricated photodetector. Under illumination, electron-hole will generate and transform in the semiconductors. As shown in Fig. S8, ESI.†, the current linearly increase with the voltage in current-voltage (I-V) curves, indicating good Ohmic contacts between the Au electrodes and $\mathrm{Pbl}_{2}$ nanobelts. At a bias voltage of $5 \mathrm{~V}$, the photocurrents of the as-fabricated photodetector are shown in Fig. $5 \mathrm{c}$ under different incident light wavelength with an intensity of $35 \mathrm{~mW} \mathrm{~cm}^{-2}$. With an illumination laser wavelength smaller than the bandgap of the as-prepared $\mathrm{Pbl}_{2}$ nanobelts $(514 \mathrm{~nm})$, the photocurrent increases with the increase of laser wavelength. On the other hand, no photocurrent can be detected when the illumination laser wavelength is larger than $514 \mathrm{~nm}$. Hence, the $445 \mathrm{~nm}$ laser is selected to illuminate the photodetector for better understanding the photosensing behavior of the $\mathrm{Pbl}_{2}$ nanobelts. The dependence of its photocurrent on different light intensities is measured and depicted in Fig. $5 \mathrm{~d}$. It is well known that the measured data can be well fitted by Equation of $I_{p}=$ $\alpha \Phi^{\beta}$, where $I_{p}$ is the photocurrent, $\alpha$ and $\beta$ are the fitting parameters, and $\Phi$ is the light intensity. ${ }^{46-51}$ As a result, the asfabricated photodetector reveals a power dependence of $I_{p}=$ $0.23 \Phi^{0.799}$ from the fitting of the measured data, depicting the sublinear relationship between the photocurrent and light intensity, which is often observed in layered-material based photoconductors due to the complex processes of electron-hole generation, trapping, and recombination in the semiconductors. ${ }^{46-48} \mathrm{It}$ is worth to point out that the value of $\beta$ is higher than the reported 2D nanosheets in literatures, $19,21,22$ indicating the high crystallinity of the as-prepared $\mathrm{Pbl}_{2}$ nanobelts. Furthermore, two important figure of merits, responsivity $(R)$ and detectivity $\left(D^{*}\right)$, are the key parameters for

Table 1 Comparison of various figure of merits of different representative $2 \mathrm{D}$ layered $\mathrm{Pbl}_{2}$ based photodetectors.

\begin{tabular}{|c|c|c|c|c|c|c|c|}
\hline Morphology & Light $(\mathrm{nm})$ & Bias (V) & Dark current $(\mathrm{pA})$ & On/off ratio & Rise time (ms) & Decay time (ms) & Reference \\
\hline Nanobelt & 445 & 5 & 4 & $10^{3}$ & 425 & 41 & This work \\
\hline Single crystal & 440 & 15 & 1380 & $10^{2}$ & & 0.354 & 16 \\
\hline Monolayer nanosheet & 450 & 5 & & 10 & 18 & 22 & 22 \\
\hline Nanosheet & 450 & 5 & 10 & $10^{3}$ & 18 & 22 & 19 \\
\hline Nanosheet & 405 & 1 & 5 & 2000 & & & 24 \\
\hline Single crystal & 450 & 10 & 560 & $10^{4}$ & 0.323 & 0.52 & 25 \\
\hline Flake & 470 & 5 & 0.14 & 900 & 13.5 & 20 & 26 \\
\hline
\end{tabular}


evaluating the sensitivity of the as-fabricated photodetector. $\mathrm{R}$ is defined as the photocurrent generated per unit power of incident light on the effective area of a photodevice, and $D^{*}$ reflects the photodetector's sensitivity. $R$ and $D^{*}$ can be calculated by the following equations: $R=I_{p}(\Phi S)^{-1}$ and $D^{*}=\operatorname{RS}^{1 / 2}\left(2 e I_{d}\right)^{-1 / 2}$, where $I_{p}$ is the photocurrent, $\Phi$ is the light intensity, $\mathrm{S}$ is the active area of the photodetector, $\mathrm{e}$ is the absolute value of the charge of an electron, and $I_{d}$ is the dark current. ${ }^{52-55}$ For the large-size $\mathrm{Pbl}_{2}$ nanobelts based photodetector, the maximum $\mathrm{R}$ and corresponding $\mathrm{D}^{*}$ are calculated to be about $13 \mathrm{mAW}^{-1}$, and $3.048 * 10^{10}$ Jones across the entire measured range, respectively, comparable to the graphene photodetectors $\left(0.5-6.1 \mathrm{mAW}^{-1}\right)^{56,57}$ and the singlecrystal CdTe nanosheets $\left(0.6 \mathrm{mAW}^{-1}\right) .{ }^{58}$ The repeatability and response speed are another two essential parameters for the performance assessment of photodetectors. The repeatability can be appraised by measuring the photocurrent as a function of time (i.e., I-t curves) under chopped illumination in Fig. 5e. It is obvious that the device ON- and OFF-state can be effectively modulated by the chopped illumination with a good repeatability and an impressive ON/OFF current ratio of $10^{3} \sim$ $10^{4}$. It is worth to pointing out that the photodetector also has a low dark current of 4 pA when the laser is on the "OFF" state. The low value of dark current indicates a low noise and a high sensitivity, which are vital for the practical electric-devices. In addition, a high-resolution I-t curve is then utilized to study the response speed of the photodetector. Usually, the time needed for the current to increase from $10 \%$ to $90 \%$ of the peak value and vice versa are defined as the rise time and decay time constants, respectively. ${ }^{59}, 60$ Based on the measurement presented in Fig. $5 f$, the rise and decay time constants can be identified as 425 and $41 \mathrm{~ms}$ accordingly, implying the high quality of the as-prepared lager-size $\mathrm{Pbl}_{2}$ nanobelts. Regardless, all these obtained performance indicators of nanobelts detectors are highly comparable to those of state-of-the-art $\mathrm{Pbl}_{2}$ as reported in the recent literature (Table 1), illustrating the impressive performance and promising prospect of our largersize $\mathrm{Pbl}_{2}$ nanobelts for the highly-efficient photodetection. It is worth to pointing out that the rise and decay times are related to the recombination of nonequilibrium photo-generated carriers. The combination processes can be affected by many factors, such as trap density, trap energy level in the forbidden gap, surface states, and adsorbed molecules, etc. Those factors are not only related to the quality of the photosensing materials, but also related to device fabrication processes. Although our $\mathrm{Pbl}_{2}$ nanobelts have high quality, the device fabrication processes can also degrade the performance of the response speed. Further optimizations of device fabrication process are needed in the future.

\section{Conclusions}

In conclusion, large-scale synthesis of large-size $\mathrm{Pbl}_{2}$ nanobelts are successfully demonstrated by manipulating the source materials mass, growth temperature, and growth time on amorphous $\mathrm{Si} / \mathrm{SiO}_{2}$ substrate in a two-step vapor deposition process. With a slow heating rate of the growth temperature, PVD growth process of $\mathrm{Pbl}_{2}$ nanosheets occurs firstly, followed by a CVD growth of lage-size $\mathrm{Pbl}_{2}$ nanobelts at a higher growth temperature by using the as-grown $\mathrm{Pbl}_{2}$ nanosheets as a seed layer. The results of SAED and PL measurements confirm highly uniform, high-quality crystallinity of the as-prepared large-size $\mathrm{Pbl}_{2}$ nanobelts. The as-prepared $\mathrm{Pbl}_{2}$ nanobelts based photodetector exhibits a low dark current of $4 \mathrm{pA}$, an impressive ON/OFF current ratio of $10^{3} \sim 10^{4}$, a photoresponsivity of $13 \mathrm{~mA}$ $\mathrm{W}^{-1}$, and a fast response with the rise and decay time constants of 425 and $41 \mathrm{~ms}$, respectively, with a large area $\mathrm{Pbl}_{2}$ nanobelt of $879.8 \mathrm{\mu m}^{2}$. All the discussed parameters reveal the technological potency of these large-size $\mathrm{Pbl}_{2}$ nanobelts for next-generation high-performance optoelectronics.

\section{Notes}

Zai-xing Yang and Ning Han conceived and designed the research. Mingming Han grew the nanobelts. Jiamin Sun implemented the XRD measurement and analysis. Mingming Han and Luozhen Bian performed the SEM, PL and Raman measurement and analysis. Jiamin Sun and Luozhen Bian measured UV-vis absorption and analysis. Mingming Han, Jiamin Sun and Luozhen Bian carried out the device fabrication. Zhou Wang contributed to photodetection test. Lei Zhang was dedicated to TEM measurement. Yanxue Yin, Zhaofeng Gao and Fulin Li contributed to data analysis of TEM and photodetection. Zai-xing Yang, Ning Han, Qian Xin, Longbin He and Aimin Song prepared the manuscript with the help from all of the other coauthors.

\section{Conflicts of interest}

There are no conflicts to declare.

\section{Acknowledgements}

We acknowledge the National Key R\&D Program of China (No. 2017YFA0305500), Shandong Provincial Natural Science Foundation, China (Grant ZR2017MF037), Science Technology and Innovation Committee of Shenzhen Municipality (Grant JCYJ20170307093131123), "Qilu young scholar" program of Shandong University. We also acknowledge the National Natural Science Foundation of China (Grants51602314 and 61504151), the CAS-CSIRO project of the Bureau of International Co-operation of Chinese Academy of Sciences (122111KYSB20150064).

\section{References}

1. M. J. Allen, V. C. Tung and R. B. Kaner, Chem. Rev., 2010, 110, 132-145.

2. Q. H. Wang, K. Kalantar-Zadeh, A. Kis, J. N. Coleman and M. S. Strano, Nat. Nanotechnol., 2012, 7, 699-712.

3. G. R. Bhimanapati, Z. Lin, V. Meunier, Y. Jung, J. Cha, S. Das, D. Xiao, Y. Son, M. S. Strano, V. R. Cooper, L. Liang, S. G. Louie, E. Ringe, W. Zhou, S. S. Kim, R. R. Naik, B. G. Sumpter, 
H. Terrones, F. Xia, Y. Wang, J. Zhu, D. Akinwande, N. Alem, J. A. Schuller, R. E. Schaak, M. Terrones and J. A. Robinson, ACS Nano, 2015, 9, 11509-11539.

4. K. F. Mak and J. Shan, Nat. Photonics, 2016, 10, 216-226.

5. K. S. Novoselov, A. Mishchenko, A. Carvalho and A. H. Castro Neto, Science, 2016, 353, 9439.

6. Q. Guo, A. Pospischil, M. Bhuiyan, H. Jiang, H. Tian, D. Farmer, B. Deng, C. Li, S.-J. Han, H. Wang, Q. Xia, T.-P. Ma, T. Mueller and F. Xia, Nano Lett., 2016, 16, 4648-4655.

7. J. S. Ponraj, Z.-Q. Xu, S. C. Dhanabalan, H. Mu, Y. Wang, J. Yuan, P. Li, S. Thakur, M. Ashrafi, K. McCoubrey, Y. Zhang, S. Li, H. Zhang and Q. Bao, Nanotechnology, 2016, 27, 462001. 8. M. Pumera and Z. Sofer, Adv. Mater., 2017, 29, 1605299.

9. Y.-R. Chang, P.-H. Ho, C.-Y. Wen, T.-P. Chen, S.-S. Li, J.-Y. Wang, M.-K. Li, C.-A. Tsai, R. Sankar, W.-H. Wang, P.-W. Chiu, F.-C. Chou and C.-W. Chen, ACS Photonics, 2017, 4, 2930-2936. M. Sun, D. Xie, Y. Sun, W. Li and T. Ren, Nanotechnology 2018, 29, 015203.

11. Z. Fang, Z. Liu, Y. Wang, P. M. Ajayan, P. Nordlander and N. J. Halas, Nano Lett., 2012, 12, 3808-3813.

12. Z. Fang, Y. Wang, Z. Liu, A. Schlather, P. M. Ajayan, F. H. Koppens, P. Nordlander and N. J. Halas, ACS Nano, 2012, 6, 10222-10228.

13. J. Song, L. Xu, J. Li, J. Xue, Y. Dong, X. Li and H. Zeng, Adv. Mater., 2016, 28, 4861-4869.

H. Deng, X. Yang, D. Dong, B. Li, D. Yang, S. Yuan, K. Qiao, Y.B. Cheng, J. Tang and H. Song, Nano Lett., 2015, 15, 79637969.

G. Wang, D. Li, H.-C. Cheng, Y. Li, C.-Y. Chen, A. Yin, Z. Zhao, Z. Lin, H. Wu, Q. He, M. Ding, Y. Liu, Y. Huang and X. Duan, Sci. Adv., 2015, 1, 1500613

16 J. Zhang, T. Song, Z. Zhang, K. Ding, F. Huang and B. Sun, J. Mater. Chem. C, 2015, 3, 4402-4406.

17. S. Yakunin, D. N. Dirin, Y. Shynkarenko, V. Morad, I. Cherniukh, O. Nazarenko, D. Kreil, T. Nauser and M. V. Kovalenko, Nat. Photonics, 2016, 10, 585-589.

18. H.-C. Cheng, G. Wang, D. Li, Q. He, A. Yin, Y. Liu, H. Wu, M. Ding, Y. Huang and X. Duan, Nano Lett., 2016, 16, 367-373.

19. M. Zhong, L. Huang, H.-X. Deng, X. Wang, B. Li, Z. Wei and J. Li, J. Mater. Chem. C, 2016, 4, 6492.

20. W. Zheng, Z. Zhang, R. Lin, K. Xu, J. He and F. Huang, Adv. Electron. Mater., 2016, 2, 1600291.

21. C. Lan, R. Dong, Z. Zhou, L. Shu, D. Li, S. Yip and J. C. Ho, Adv. Mater., 2017, 29, 1702759.

22. M. Zhong, S. Zhang, L. Huang, J. You, Z. Wei, X. Liu and J. Li, Nanoscale, 2017, 9, 3736-3741.

J. K. Meyers, S. Kim, D. J. Hill, E. E. M. Cating, L. J. Williams, A. S. Kumbhar, J. R. McBride, J. M. Papanikolas and J. F. Cahoon, Nano Lett., 2017, 17, 7561.

R. Frisenda, J. O. Island, J. L. Lado, E. Giovanelli, P. Gant, P. Nagler, S. Bange, J. M. Lupton, C. Schller, A. J. MolinaMendoza, L. Aballe, M. Foerster, T. Korn, M. A. Nino, D. P. de Lara, E. M. Perez, J. Fernandez-Rossier and A. Castellanos-Gomez, Nanotechnology, 2017, 28, 455703.

25. Q. Wei, B. Shen, Y. Chen, B. Xu, Y. Xia, J. Yin and Z. Liu, Mater. Lett., 2017, 193, 101-104.

26. Y. Wang, L. Gan, J. Chen, R. Yang and T. Zhai, Sci. Bull., 2017 62, 1654-1662.

27.

J. Liu, Z. Liang, B. Xu, H. Xiang, Y. Xia, J. Yin and Z. Liu, RSC Adv., 2016, 6, 59445-59449.

28. V. K. Agrawal, G. K. Chadha and Trigunay.Gc, Acta Crystallogr., Sect. A, 1970, A 26, 140.
29.

30.

31

32

33.

34

35.

36.

39.

40.

41.

42

44.

45.

46.

48

M. R. Tubbs, Phys. Status Solidi B, 1972, 49, 11.

Z.-X. Yang, W. Zhong, P. Zhang, M.-H. Xu, C.-T. Au and Y.-W. Du, CrystEngComm, 2012, 14, 585-589.

Z.-x. Yang, N. Han, F. Wang, H.-Y. Cheung, X. Shi, S. Yip, T. Hung, M. H. Lee, C.-Y. Wong and J. C. Ho, Nanoscale, 2013, 5, 9671-9676.

Z.-X. Yang, W. Zhong, C.-T. Au and Y.-W. Du, Chin. Phys. B, 2013, 22, 108101.

R. S. Wagner and W. C. Ellis, Appl. Phys. Lett., 1964, 4, 89.

J. Westwater, D. P. Gosain, S. Tomiya, S. Usui and H. Ruda, J. Vac. Sci. Technol., B, 1997, 15, 554-557.

R. J. M. Konings, E. H. P. Cordfunke and R. R. Vanderlaan, J. Alloys Compd., 1995, 230, 85-88.

L. E. Greene, M. Law, D. H. Tan, M. Montano, J. Goldberger, G. Somorjai and P. D. Yang, Nano Lett., 2005, 5, 1231-1236. M. Law, L. E. Greene, J. C. Johnson, R. Saykally and P. D. Yang, Nat. Mater., 2005, 4, 455-459.

Z. X. Yang, W. Zhong, C. T. Au, X. Du, H. A. Song, X. S. Qi, X. J. Ye, M. H. Xu and Y. W. Du, J. Phys. Chem. C, 2009, 113, 21269-21273.

S. Xu and Z. L. Wang, Nano Res., 2011, 4, 1013-1098.

D. R. Lide, CRC Handbook of Chemistry and Physics, 85th Edition, CRC Press, 2004.

W. M. Sears, M. L. Klein and J. A. Morrison, Phys. Rev. B, 1979, 19, 2305-2313.

N. Preda, L. Mihut, M. Baibarac, I. Baltog and S. Lefrant, J. Phys.: Condens. Matter, 2006, 18, 8899-8912.

R. R. Anderson and J. A. Parrish, J. Invest. Dermatol., 1981, 77, 13-19.

A. F. daSilva, N. Veissid, C. Y. An, I. Pepe, N. B. deOliveira and A. V. B. daSilva, Appl. Phys. Lett., 1996, 69, 1930-1932.

X. H. Zhu, Z. R. Wei, Y. R. Jin and A. P. Xiang, Cryst. Res. Technol., 2007, 42, 456-459.

F. Binet, J. Y. Duboz, E. Rosencher, F. Scholz and V. Harle, Appl. Phys. Lett., 1996, 69, 1202-1204.

C. Soci, A. Zhang, B. Xiang, S. A. Dayeh, D. P. R. Aplin, J. Park, X. Y. Bao, Y. H. Lo and D. Wang, Nano Lett., 2007, 7, 10031009.

O. Lopez-Sanchez, D. Lembke, M. Kayci, A. Radenovic and A. Kis, Nat. Nanotechnol., 2013, 8, 497-501.

X. Wang, P. Wang, J. Wang, W. Hu, X. Zhou, N. Guo, H. Huang, S. Sun, H. Shen, T. Lin, M. Tang, L. Liao, A. Jiang, J. Sun, X. Meng, X. Chen, W. Lu and J. Chu, Adv. Mater., 2015, 27, 6575.

C. Y. Lan, C. Li, S. Wang, T. Y. He, Z. F. Zhou, D. P. Wei, H. Y. Guo, H. Yang and Y. Liu, J. Mater. Chem. C, 2017, 5, 14941500.

B. Du, W. Yang, Q. Jiang, H. Shan, D. Luo, B. Li, W. Tang, F. Lin, B. Shen, Q. Gong, X. Zhu, R. Zhu and Z. Fang, Adv. Opt. Mater., 2018, 6, 1701271.

G. Konstantatos and E. H. Sargent, Nat. Nanotechnol., 2010, 5, 391-400.

J. Michel, J. Liu and L. C. Kimerling, Nat. Photonics, 2010, 4, 527-534.

L. Rigutti, M. Tchernycheva, A. D. L. Bugallo, G. Jacopin, F. H. Julien, L. F. Zagonel, K. March, O. Stephan, M. Kociak and R. Songmuang, Nano Lett., 2010, 10, 2939-2943.

L. Peng, L. Hu and X. Fang, Adv. Mater., 2013, 25, 5321-5328. F. Xia, T. Mueller, Y.-m. Lin, A. Valdes-Garcia and P. Avouris, Nat. Nanotechnol., 2009, 4, 839-843.

M. Freitag, T. Low, F. Xia and P. Avouris, Nat. Photonics, 2013, 7, 53-59. 
58. R. Cheng, Y. Wen, L. Yin, F. Wang, F. Wang, K. Liu, T. A. Shifa, J. Li, C. Jiang, Z. Wang and J. He, Adv. Mater., 2017, 29, 1703122.

59. M. Buscema, D. J. Groenendijk, S. I. Blanter, G. A. Steele, H. S. J. van der Zant and A. Castellanos-Gomez, Nano Lett., 2014, 14, 3347-3352.

60. R. Saran and R. J. Curry, Nat. Photonics, 2016, 10, 81-92. 